Received 1 March 2019; accepted 4 June 2019.

Available online 1 July 2019

\title{
Urban Enclosure Movement: The Impact of Gating a Previously Non- Gated Residential Area
}

\author{
Ghada Yassein \\ Department of Architecture \\ Menoufia University \\ ghadayassine@yahoo.com
}

\begin{abstract}
Gated and controlled access housing developments are commonly perceived as a desirable setting by homeowners and home buyers. However, it has been claimed that gating contradicts the concept of permeability, connectivity, and livability of cities. How gating affects residential satisfaction? Answering this question will be hard in the case of studying gated communities because gates and walls are interrelated with several amenities that characterize this type of housing. Therefore, the present research is a qualitative case study that explores the impact of gating a previously non-gated housing area. It highlights residents' experiences, feelings, and perceptions of their residential environment before and after the installation of the gates. Results show that three domains out of five are positively affected by gating, specifically: (a) place identity; (b) privacy and environmental control; and (c) safety and security feelings. The findings indicate also that privacy and convenience of controlled access is a paramount advantage of gating more than protection from crime. Most importantly is that residents are used now to the benefits achieved from gating that they will hardly force it aside by the need to promote livable and sustainable city life.
\end{abstract}

KEYWORDS: housing environment; controlled access; residents' satisfaction; qualitative case study

\footnotetext{
ملخص البحث

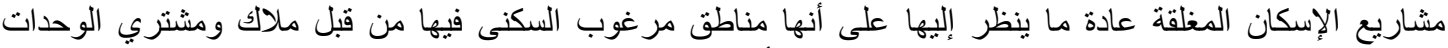

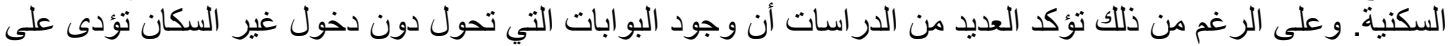

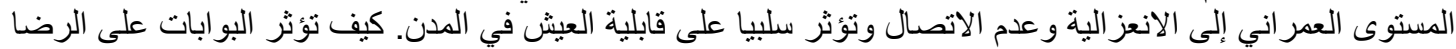

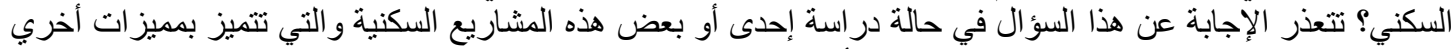

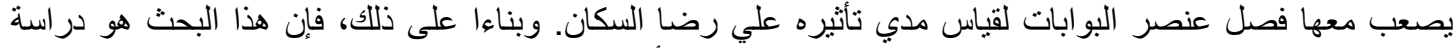

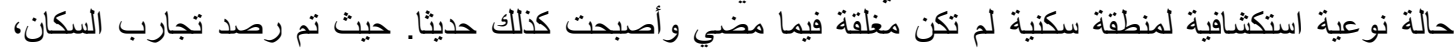

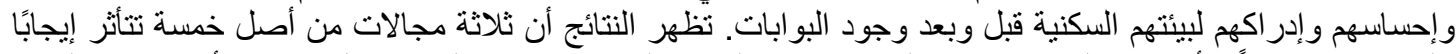

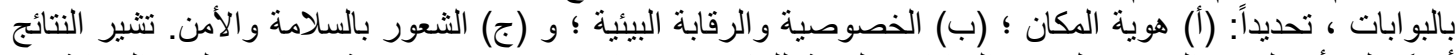

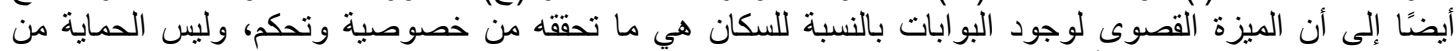

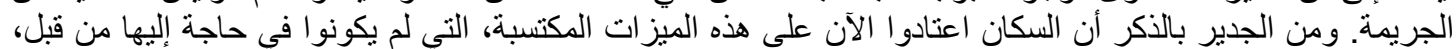
و التي يصعب تتازلهم عنها حاليا في مقابل تعزيز قابلية العيش في الندان المدن واستدامتها.
} 


\section{INTRODUCTION}

Many scholars stress on the necessity that the factors determining housing and environmental quality satisfaction should be taken into account during the planning process in order to increase user satisfaction.

Gated and controlled access housing developments are commonly perceived as a desirable setting by homeowners. However, the analysis of existing literature has consistently shown that gating clearly plays a role in the urban enclosure movement; it contradicts the concept of permeability, connectivity, and livability of cities.

Therefore, it is of particular importance to assess how gating affects residential satisfaction. To address this issue, it will be hard to assess how gating affect residential satisfaction in gated communities as gates and walls are interrelated with several amenities that characterize this type of housing. Consequently, 'Madinet Elzahraa' housing area was selected as a case study because it wasn't gated for more than 40 years then become gated recently - not by the residents themselves but for military purpose. In other words, it was not the residents' choice to live in a gated residential area, therefore their experiences, perceptions, and feelings towards gating will be more insightful.

Purpose of the study: The purpose of this study is to explore people's attitudes towards certain aspects of their residential environment before and after gating that warrant replication or improvement in any future residential development. Specifically, it identifies the role of the gates in residential satisfaction.

Significance of the study: It is commonsensical that some planning issues will emerge in completed projects, with some becoming apparent only after a period of time. It is imperative therefore that planners and policymakers with respect to housing delivery recognize the place of the end-users in the delivery process. Accordingly, this study is deemed significant, as it provides feedback on an important aspect of residential satisfaction which is 'gating'.

Research strategy: The present research is a qualitative case study research that involves intensive analysis of an individual unit - i.e. a residential area in Cairo city. This case study is most relevant to the research purpose as previously mentioned.

\section{Definition of key terms:}

- Gating: Gating in this research stands for gates installation to control access.

- Enclosure: (a) The process of dividing up open or common land. Source: Urban Dictionary Online retrieved from http://www.urbandictionary.com/define.php?term=Enclosure.

(b) The physical geography of enclosure was central to the new legal settlement of private property rights that held precedence over traditional rights to share land: the borders that lined the land were to stop the 'free passage of men and animals' and reflect its now 'exclusive ownership and occupation' (Hodkinson, 2012), p. 504. 
Delimitations: Some of the factors that determine the degree to which a person is satisfied with his/her residential environment are not addressed in this research study, specifically building features (such as the number of bedrooms, size/location of kitchens, and quality of materials, etc.).

Limitations of the study: Due to the scope of the research, limitations of time and resources, the researcher is not able to collect data from the entire population sample for a mixed (combined) research design -i.e. integration of both quantitative and qualitative data.

In this study, the interviews were conducted in the Arabic language and interpreted in English which may change the original meanings to some extent.

\section{LITERATURE REVIEW}

According to (Creswell, 2014), a good literature map design should be divided into broad topics including the methodological approach adopted. Based on this, the next part is confined to highlighting key themes of the literature and a detailed discussion of case study as a qualitative methodology (Figure 1).

Figure (1) The research literature map as cited in (Creswell, 2014).

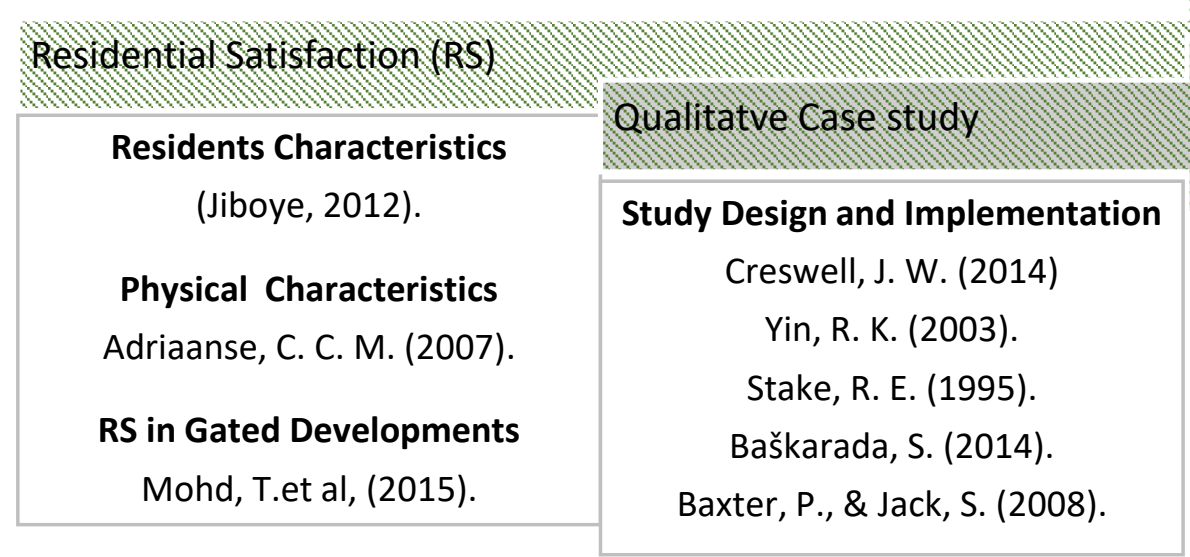

\subsection{Residential Satisfaction}

Residential satisfaction is often employed to evaluate residents' perceptions of and feelings for their housing units and the environment (Ogu, 2002). This section provides theoretical insights used as a tool for reading and analyzing the research problem.

\subsubsection{Factors affecting residential satisfaction}

The literature is replete with considerable evidence illustrating that residential satisfaction is influenced by a broad array of objective and subjectively perceived conditions. It is not only the engineering elements that determine residents' satisfaction with their accommodation, but also social, behavioural, cultural, and 
other elements in the entire societal-environmental system. In other words, the concept of residential satisfaction does not lie in the individual's dwelling; "it is a composite of the overall physical and social components that make up the housing system" (Jiboye, 2012), P. 38.

\section{A. Residents characteristics}

According to (Jiboye, 2012), factors that have been found related to housing satisfaction include age, marital status, the number of children and family size, socioeconomic status, income, education, employment, length of residency, social participation and interaction, past living conditions, as well as residential mobility and future intention to move.

\section{B. Physical, social and environmental characteristics}

(Adriaanse, 2007) referred to three (3) factors that determine the degree to which a person is satisfied with his/her residential environment:

- Factor 1 labelled as 'internal neighbourhood reputation' can be interpreted as the residents' general opinions and feelings about living in the neighbourhood. It represents their experience of the physical environment and the population characteristics.

- Factor 2 labelled as 'social climate' representing individual's perception of how others treat him/her, one another, and the spatial artefacts within the area that the individual experiences as his/her living environment.

- Factor 3 is labelled 'dwelling satisfaction'(Adriaanse, 2007).

(Phillips. D. R., Siu, Yeh, \& Cheng, 2004) reported that there are three (3) domains (with various elements) that might impact on older persons' residential satisfaction: the structural domain (interior and exterior dwelling characteristics, security concerns); the informal domain (informal social support including family, friends, and neighbours); and the formal domain (social services and community facilities) around or near the neighbourhood.

Moreover, some scholars have argued that residents' perception of their environment defines their quality of lives and that quality of life was related to feelings of security, physical safety, protection and environmental comfort (Kowaltowski et al., 2006). According to them, security and safety feelings were related not only to crime rates and the quality of policing but also to street lighting and visibility of movements in public areas.

\subsubsection{Residential Satisfaction in Gated developments}

Quite a few scholars addressed residential satisfaction in gated communities. (Mohd, Johari, Ghani, \& Rahman, 2015) revealed that residents' choose to stay in gated areas, mainly because of guaranteed security, privacy, exclusive lifestyle, community ties, improved environmental control and maintenance. The study carried out by (Berköz, 2009) ascertained that accessibility to green open areas and security are significant to gated communities residents satisfaction. Also, the work of (ElSayed, 2016) in El Rehab City (a gated community in Egypt), revealed that its residents don't 
accept sharing services, facilities and amenities with the non-residents. As they certainly pay for it, hence it is a logical consequence they want to exclude those who don't pay from using them; "It also decreases the residents' feeling of social control", p. 1195.

To end with, the literature is abudant with analyses of many variables that are strongly related to residential satisfaction and occupiers' evaluations of housing environment. For the purpose of the current study, five only domains will be investigated: (a) urban character (place identity); (b) management and maintenance; (c) privacy and environmental control; (d) community ties; (e) safety and security.

\subsection{Qualitative Case Study Methodology}

While quantitative research is mainly concerned with the testing of hypotheses and statistical generalisations, qualitative research is focusing on understanding the nature of the research problem rather than quantifying observed characteristics. It is mainly concerned with interpreting meanings from people's beliefs and practices (Baškarada, 2014).

The qualitative case study methodology is preferred in examining contemporary events when the relevant behaviours cannot be manipulated. It has a general advantage when a 'how' or 'why' question is being asked about a contemporary set of events over which the investigator has little or no control (Yin, 2009).

As such, a qualitative case study is based on the constructivist paradigm in which truth is relative and it is dependent on one's perspective. The rigour of this approach is the close collaboration between the researcher and the participant, enabling participants to tell their stories. Through these stories, the participants are able to describe their views of reality and this enables the researcher to better understand the participants' actions (Baxter \& Jack, 2008).

The following section is devoted to identifying the key elements for designing and implementing qualitative case study research based on (Yin, 2009) universally accepted six-stage case study process, enriching it by additional guidelines from other methodological literature.

\subsubsection{Case study process}

A case study is not a method but a research strategy. In other words, the case study is not a methodological choice but a choice of what is to be studied (Kohlbacher, 2005). According to (Yin, 2009), the case study process comprises six interdependent stages as illustrated in (figure 2) : (1) Plan; (2) Design; (3) Prepare (and share your preparation); (4) Collect (sometimes going back to Design when collecting data); (5) Analyse; (6) Share. 
Figure (1) The case study process, adapted from (Yin, 2009), p. 1.

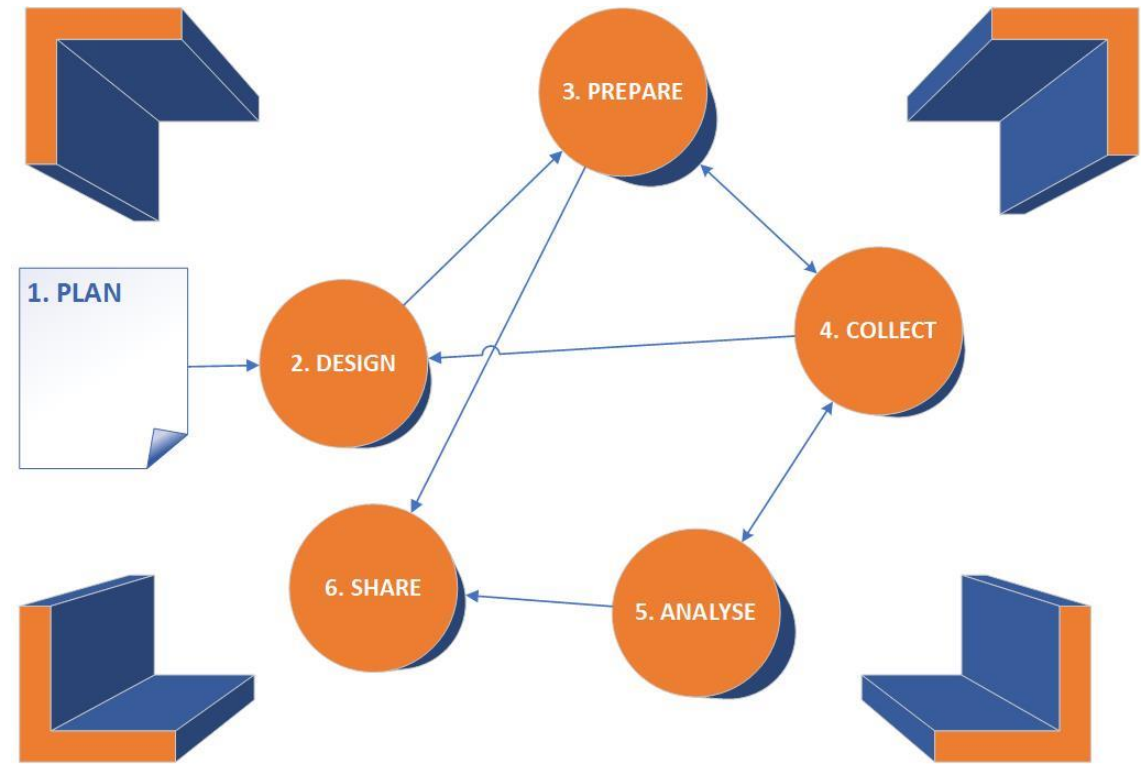

Stage 1. 'Plan': In this stage, the rationale for doing a case study is identified (why case study strategy is used compared with other methods), the research problem is clearly defined as well as careful consideration of the research questions and study objectives (Baškarada, 2014). Another key point of the planning stage is to determine the type of case study that will be conducted. According to (Yin, 2003), case studies can be 'exploratory', 'descriptive', or 'explanatory', and they have been preferred when the investigator has little control over events, and the focus is on a contemporary phenomenon within a real-life context. On the other hand, (Stake, 1995) identifies case studies as 'intrinsic', 'instrumental', or' collective'.

Stage 2. 'Design': For case studies, there are five components of research design that are especially important: (a) a study's question; (b) its propositions (i), if any (some studies have a legitimate reason for not having any propositions, this is the condition which a topic is the subject of exploration); (c) its unit(s) of analysis - the unit of analysis defines what the case ${ }^{(i i)}$ is e.g. an event, a process, an individual, a group, or an organization-the desired case should be a real-life phenomenon, not an abstraction. Individual cases may be selected based on convenience, purpose, and probability (Baškarada, 2014), p. 4; (d) the logic linking the data to the propositions. Research design logically links the research questions to the research conclusions through the steps undertaken during data collection and data analysis; and (e) the criteria for interpreting the findings.

A second concern in the design stage is the quality of the research design. Four tests have been commonly used to establish the quality of any empirical social research (Yin, 2009):

- Construct validity (identifying correct operational measures for the concepts being studied).

- Internal validity (for explanatory or causal studies only, not for descriptive or exploratory studies). 
- External validity (defining the domain to which a study's findings can be generalized).

- Reliability (demonstrating that the operations of a study - such as data collection procedures - can be repeated with the same results).

Stage 3. 'Prepare': This stage focuses on developing a case study protocol, conducting a pilot case, and gaining any relevant approvals before starting the data collection stage. An important point is that case study research is not merely a matter of recording data in a mechanical fashion, therefore the case study investigator should be sufficiently familiar with the study domain, he should also be able to interpret the information as it is being collected and to know immediately how to adjust his data collection activities accordingly - if several sources of information contradict one another and lead to the need of additional evidence to suit the case study (Baškarada, 2014; Yin, 2009).

Stage 4. 'Collect': It involves using multiple sources of evidence, establishing a case study database to store relevant evidence, and a chain of evidence should be used to explain how any conclusions have been drawn. Relevant data may be collected through documents, archival records, interviews, observations, and physical artefacts (ibid). One of the most important sources of case study evidence is interviews (iii); they are guided conversations that have been described as a "pipeline for transmitting knowledge" (Silverman, 1997), p. 113. There are at least three types: in-depth interview; focused interview; and formal survey interview.

In-depth interview is used to ask the interviewee about the facts of a matter as well as his/her opinions about events. In some situations, the researcher is able to refocus the questions, or prompt for more information if something new emerges. Upon the completion of the interview, it should be discussed as soon as possible to compare impressions and eliminate any potential misunderstandings.

Another source of evidence is observation. Participant-observation is a special mode of observation in which the researcher is not merely a passive observer. Instead, he may assume a variety of roles within a case study situation and may actually participate in the events being studied, such as being a resident in a neighbourhood.

Ideally, the use of multiple sources of evidence deals with the potential problems of construct validity because the multiple sources of evidence basically provide multiple measures of the same phenomenon. Additionally, creating a case study database consisting of two separate collections (i.e. the data or evidentiary base and the report of the investigator, whether in an article, report or book form) markedly increases the reliability of the entire case study.

Stage 5. 'Analyses': In the context of case studies "data analysis consists of examining, categorising, tabulating, testing, or otherwise recombining evidence to draw empirically-based conclusions" (Yin, 2009), p. 126. It has been argued that the concept Observe, Think, Test, and Revise (OTTR) is imperative to case study data collection and analysis (see Figure 3 ). "This process can be stopped when a plausible explanation has been developed,[...], or it is obvious that any additional data will not lead to new information/insights" (Baškarada, 2014), p. 12. 
Figure (2) the concept Observe, Think, Test, and Revise (OTTR) for the analyse stage, adapted from (Baškarada, 2014), p. 17.

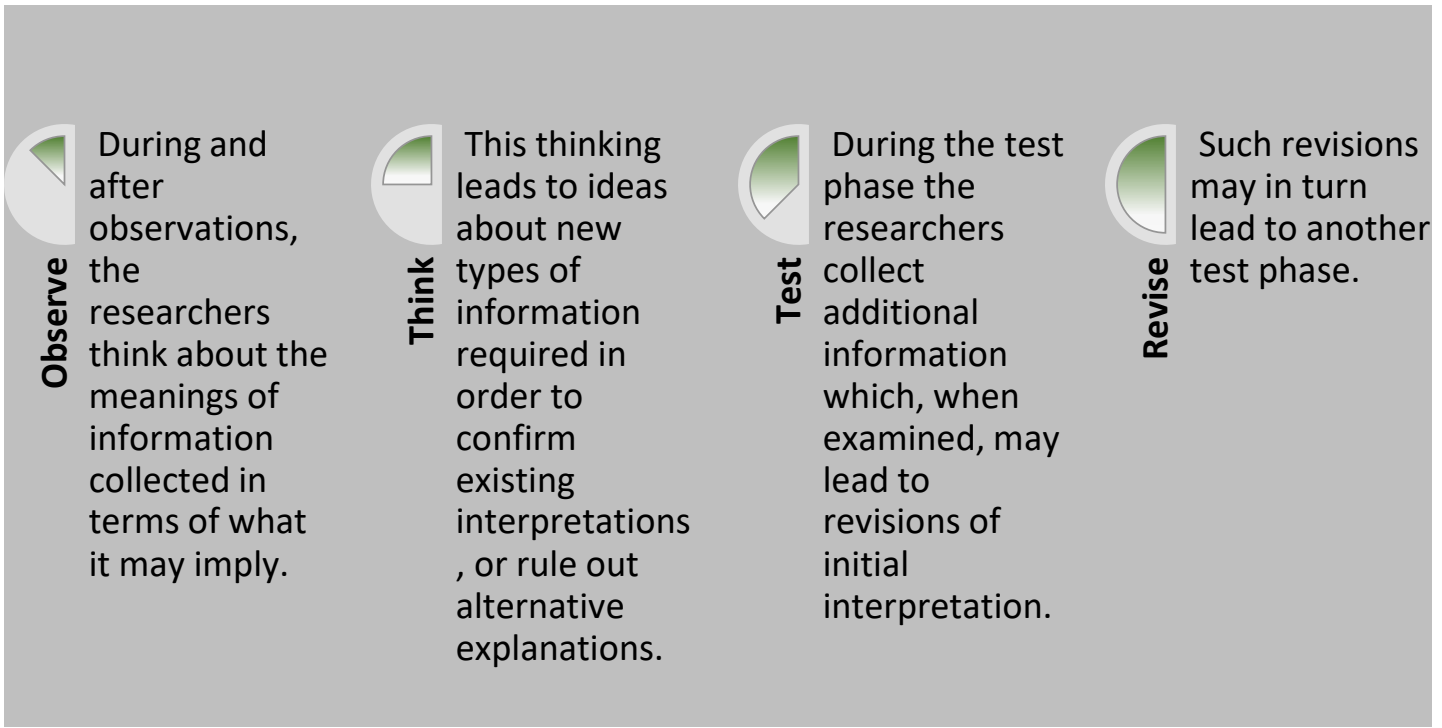

Stage 6. 'Share': It focuses on the researcher's responsibility to convert a complex phenomenon into a format that is readily understood by the reader to reach his/her own conclusions. Most importantly, as a validating procedure, the draft report should be reviewed by peers with relevant subject matter expertise as by participants and informants in the case. From a methodological standpoint, the review by the case study participants in this stage will increase the accuracy of the case study, accordingly will enhance the construct validity of the study (Yin, 2009).

\section{RESEARCH METHODOLOGY}

The present research is a simple (iv) convenience intrinsic exploratory case study. Convenience because it was selected as being expedient for data collection purposes. Intrinsic because the purpose is to better understand the case, and exploratory because it is used "to explore those situations in which the intervention being evaluated has no clear, single set of outcomes" (Baxter \& Jack, 2008), p. 548.

\subsection{Setting}

Choosing 'Madinat Elzahraa' (figure 4) as a case study is very decisive for the purpose of this research. The specificity of this case study is that it has been nongated for forty years, then gates installation was after $25^{\text {th }}$ Jan 2011 revolution for safety reason (due to a closed by military area). It was not the residents' decision to enclose themselves. This is crucial for the research objective because residents have experienced the two different settings; opened and gated. Most important to note that despite it has been planned longtime ago (before the boom of gated communities), its design reflects many planning values that 'gating' supports such as compact form; safe; quiet; private; traffic calming; pedestrian-friendly; quality of design and character; reduced road dimensions; local community amenities; and sense of place and community identity (Data obtained through participant observation). 
It is a 'private by design' residential area that had, when established, only one entrance which reinforced spatial isolation and cul-de-sac as a common inwardoriented street network pattern. Later on, a second entrance was needed due to the outside traffic congestion, thus facilitating the accessibility from two different main roads. It must be mentioned that the installation of the two gates was only what is needed to be a closed residential development.

Figure (3) 'Madinet Elzahraa', Abou Ghazalah, Mansheya El-Tahrir, Cairo Governorate.

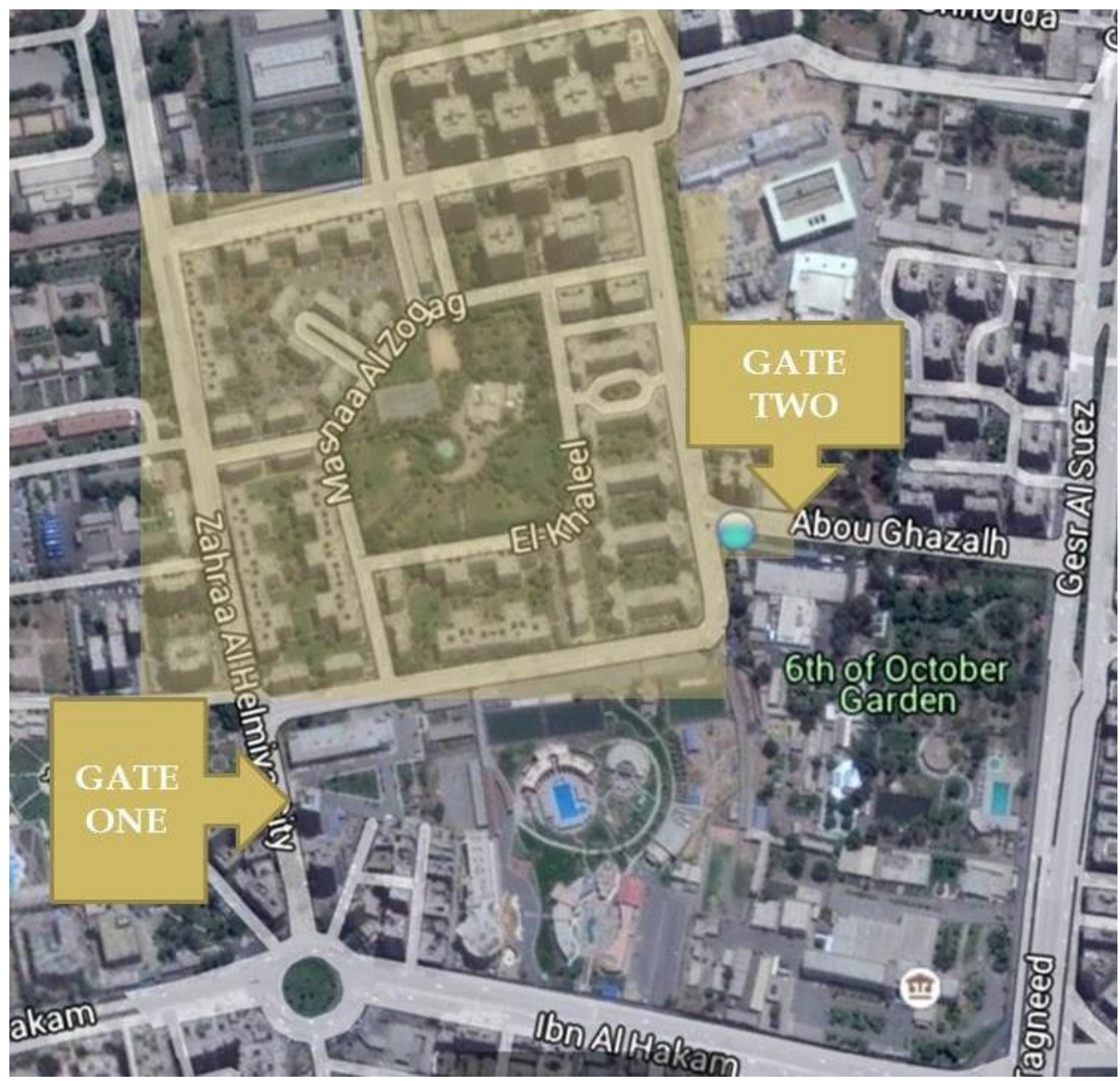

\subsection{Research Questions}

According to (Seidman, 2006), "In a qualitative study, inquirers state research questions, not objectives (i.e., specific goals for the research) or hypotheses (i.e., predictions that involve variables and statistical tests). These research questions assume two forms: (a) a central question and (b) associated sub questions" p. 85.

The central question: How gating affects residents' satisfaction with their housing environment?

Associated sub questions: (1) Have residents' perceptions of their residential environment character, management and maintenance differed before than after gating? (2) Have feelings of privacy changed after gating? (3) Is there any difference 
in social behaviour before and after gating? (4) Have feelings of safety changed after gating? (5) What are resident's views concerning gates?

\subsection{Sources of Data}

Participant observation is imperative for gaining an understanding of the physical, social, cultural, and economic contexts in which study participants live. Being a resident in the study area, this enables the researcher to develop a familiarity with the cultural milieu, and give her a thorough understanding that can come only from personal experience (Mack, Woodsong, M.Macqueen, Guest, \& Namey, 2005).

The in-depth interview is used to draw out each participant's perspective on the research topic in a more relaxed atmosphere not obtainable if filling out a survey was data collection method (Boyce \& Neale, 2006). Accordingly, an Interview protocol was prepared consisting of three parts as follows: Firstly, introduction part: including; thank you, researcher name, purpose, duration, how interview will be conducted, opportunity for questions, and oral recorded consent. Secondly, questions part; twenty questions mostly open-ended were designed to explore residents' general opinions and feelings about living in the residential area before and after gating. It also represents their experience after the installation of the gates. Literature review and participant observation help out identifying the significant questions for the interviews based on the following dimensions: urban character, management and maintenance, privacy and environmental control, community ties, and guaranteed security as follows:

- Residents' perceptions of the area in which they live, and maintenance: (seven questions)

- Perceptions of privacy and environmental control: (two questions)

- Perception of 'social climate' and community ties: (four questions)

- Perception of safety and security concerns: (four questions)

- Attitudes towards gating: (four questions)

Thirdly, the closing part: including; additional comments, next steps, and thank you. Additionally, an outline beforehand was prepared to be filled in after conducting each interview. The notes on the interview - also referred to as postscript-covers different issues. These notes were later compared across all interviewees.

\subsection{Sampling and Recruitment Strategy}

The sample was a maximal variation sample: male and female, different age group, different occupation, owners and renters. However, "10-year residency" is a must, so participants will be able to compare their perception before and after the installation of the gates.

The number of interviews depends on data saturation when additional interviews no longer reveal fresh insights (Fusch \& Ness, 2015). It has to be noted that when studies are limited in scope, deal with homogenous populations, involve domains highly familiar to the researcher and participants, fewer qualitative interviews are needed (Bonde, 2013). (Guest, Bunce, \& Johnson, 2006) suggest that for most 
research projects in which the aim is to understand common perceptions and experiences among a group of relatively homogeneous individuals, "a sample of six interviews may have been sufficient to enable development of meaningful themes and useful interpretation" (Guest et al., 2006), p. 78.

\subsection{Ethics and Human Subjects Issues}

As oral consent is generally acceptable for research with minimal risk, in-depth interviews participants received all of the information needed for verbally consents to participate. This information includes; the purpose of the research, what is expected of a research participant and the amount of time likely to be required for participation, the fact that participation is voluntary and that one can withdraw at any time with no negative repercussions, how confidentiality will be protected ${ }^{(v)}$, the name and contact information of the researcher to be contacted for questions.

\subsection{Data Analysis Strategies}

This study data analysis strategy included six steps as follows: (a) firstly, organizing data based on the interview guide to identify and differentiate between the main questions to be answered and those that were included in the interview guide but not essential for the moment. After answering original questions, other ideas and themes that had emerged from data were considered in terms of how they relate to questions and future research considerations; (b) next, picking out ideas and concepts and organizing them into categories. Also, it was important is this stage to look for "rich points", when a new or unexpected direction was revealed as the different responses were read through; (c) building overarching themes in the data by grouping different categories into one main over-arching theme; (d) ensuring validity and reliability in the data analysis and in the findings (see strategies for achieving trustworthiness); (e) finding possible and plausible explanations for findings and if they were expected based on the literature or there were any major surprises in the findings; and ( $f$ ) finally, thinking about the implications of the findings (O'connor, 2003).

\subsection{Strategies for Achieving Trustworthiness}

Employing multiple sources of evidence (i.e. in-depth interviews and participant observation) increases 'internal validity' by providing multiple measures of the same phenomenon. The researcher being a resident in this area, she has prolonged and intense exposure to the phenomenon under study within its context. Also, rapport with participants was established, thus multiple perspectives can be collected and understood and the potential for social desirability bias ${ }^{(\mathrm{vi})}$ in interviews is reduced (Krefting, 1991).

Additionally, after data were collected and analyzed, the researcher incorporated a process of member checking, where the researcher' interpretations of the data were shared with the participants, and the participants have had the opportunity to discuss and clarify the interpretation, and contribute new or additional perspectives 
on the issue under study. The main idea behind this concept is to discursively achieve 'communicative validation' which is the mutual consent and accordance about the results of the analysis between the researcher and the researched (Baxter \& Jack, 2008; Kohlbacher, 2005).

Moreover, the consistency of the findings or 'dependability' is promoted as the researcher implement a process of double coding. It means that a set of data are coded, and then after a period of time the researcher returns and codes the same data set and compares the results (Krefting, 1991).

Eventually, the provided study protocol including an overview of the interdependent stages of the study process contributes to the reliability of the study by standardising the investigation so the same results can be obtained by repeating the data collection procedure (Yin, 2009).

\section{FINDINGS}

Participants: Nine in-depth semi-structured interviews of the residents were conducted; interviews allowed them to express their views in their own terms. Participants differed in gender (4 males; 5 females), age groups (>65; 35-65; <20), occupation (professor; physician; accountant; architect; lawyer; military officer; university student), family status (5 married; 3 single; one widowed), and tenure of household ( 2 owner-occupied; 7 rented from the housing association). The minimum length of residency was 19 years and the maximum was 47 years. The duration of each of these interviews was 35 to 45 minutes.

The following table lists the demographic information of the interviewees, and each person was assigned a number to be addressed and discussed later.

Table (1) Demographic information of the interviewees.

\begin{tabular}{cllll}
\hline Interviewees & Gender & Age & Occupation & Length of Residency \\
\hline I. & Male & 63 & Lawyer & 20 \\
II. & Female & 44 & Engineer & 44 \\
III. & Male & 74 & Military Officer & 46 \\
IV. & Female & 41 & Professor & 41 \\
V. & Male & 19 & University Student & 19 \\
VI. & Female & 47 & Accountant & 43 \\
VII. & Female & 71 & Physician & 46 \\
VIII. & Male & 38 & Accountant & 38 \\
IX. & Female & 69 & Architect & 45 \\
\hline
\end{tabular}

Data Analysis: After getting information from participants, each interview was transcribed into written form for the purpose of analysis. The data analysis was started with the reading of the written transcript interviews several times followed by coding and memo writing (vii). Coding includes "priori codes" (derived from a list of 
research questions), and "emergent codes" (that come up in the data and are different than the priori codes). Subsequently, the themes were identified from the data, re-ordered, and arranged under each of the five research questions for further discussion.

A total number of (15) themes and (47) codes were identified. The computerassisted qualitative data analysis software (CAQDAS) Atlas's version 8 was used. It visualizes data analysis by means of networks, allowing expressing relationships between each domain and its related themes and codes.

Results: This study reveals that gates installation partly affects residents' satisfaction. Three residential satisfaction domains out of five have changed after gating while the two remaining haven't changed. Level of residential satisfaction increased with respect to the following domains: 'urban character'; 'guaranteed security'; 'privacy and environmental control'. On the other hand, it has not been changed for each of the 'management and maintenance 'and 'community ties' domains as shown in (figure 5).

Figure (4) Residential satisfaction domains and level of satisfaction after gating.

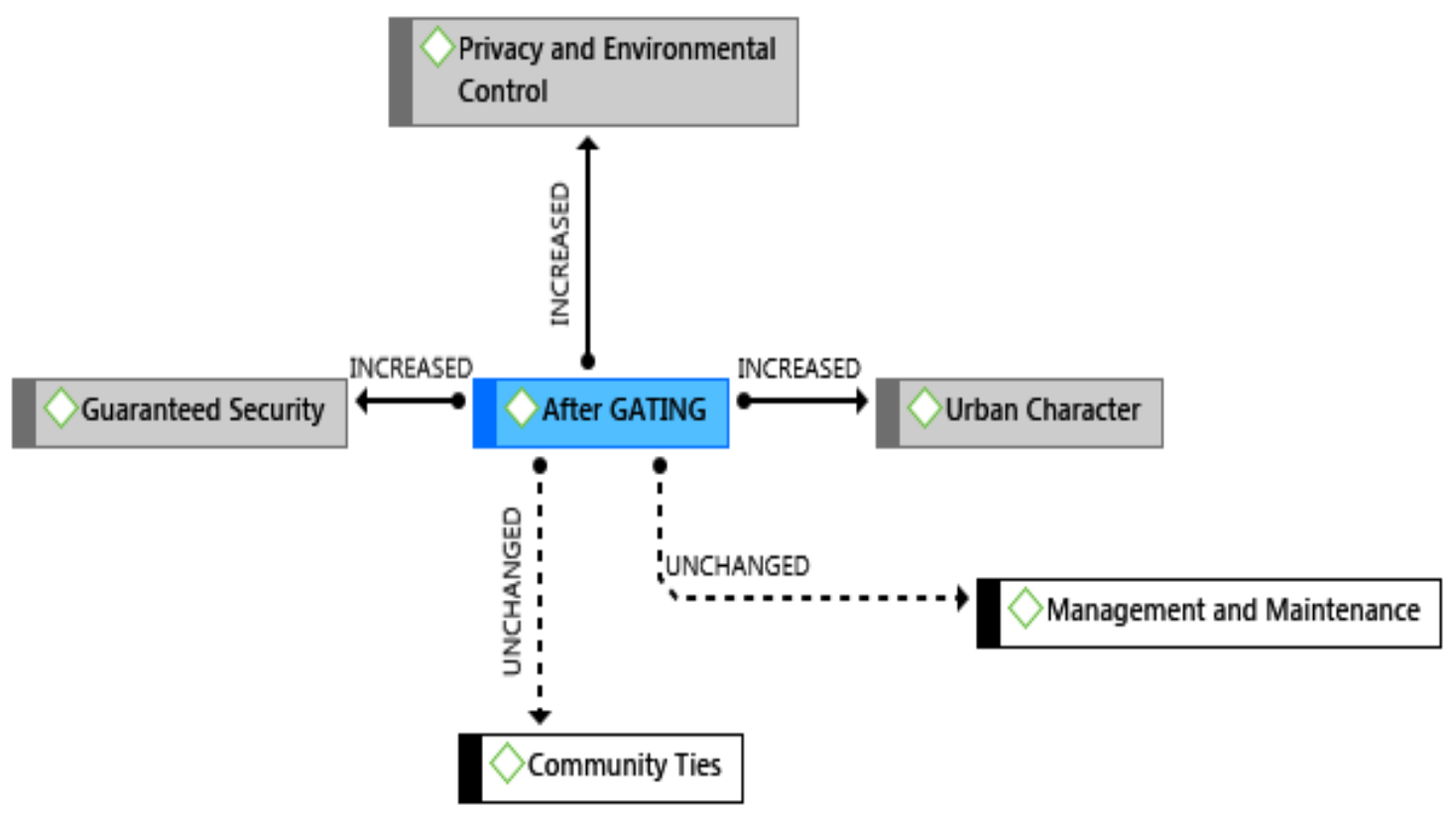

All interviewees indicate that gating has controlled unwanted strangers using the area, also the majority claim that it has made the area safer. Most interviewees declare that gating has increased privacy. Four interviewees believe that gating has improved the image of the area. At the same time, three interviewees affirmed that gating has increased property value. The only reported disadvantage of gating was claimed by two interviewees; that gating has been inconvenient for service suppliers however they asserted that it is not a big deal as they are going to get used on it. Most importantly to note that almost all of the interviewees didn't feel they needed gating before but now - whatever their views concerning the benefits of gatingall of them declared that they are used to residential enclosure even though they are going to pay for it. 


\section{DISCUSSION OF RESEARCH QUESTIONS}

RQ1: Have residents' perceptions of their residential environment character, management and maintenance differed before than after gating?

Domain 1: Urban character (three themes and fourteen codes were identified, figure 6)

Figure (5) Urban character domain and its related themes and codes visualized using the Atlas's network function.

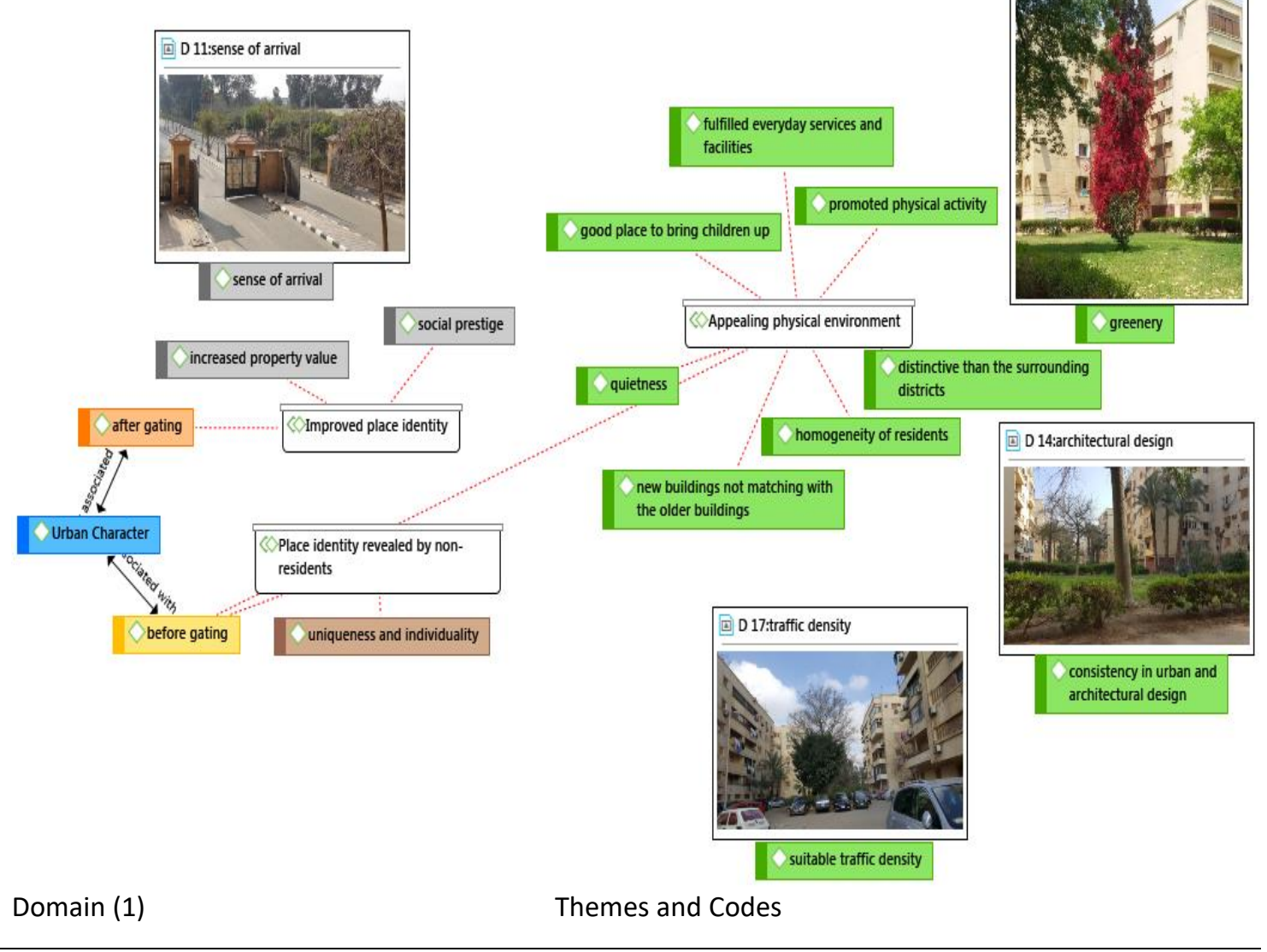

\section{Theme One: Appealing physical environment [before gating]}

Based on the shared views from interviewees who participated in the study, this residential area is characterized by its quietness, greenery, homogeneity of residents, suitable traffic density, a good place to bring children up, everyday services and facilities are fulfilled. In general, it is very distinctive than the surrounding districts, it has a pleasing degree of consistency in urban design and architectural character, it also promotes physical activity such as walking and biking. However, there are some views that the new buildings were not designed in sympathy with the older buildings (interviewees IV and V).

Theme Two: Place identity revealed by non-residents [before gating] 
It is easy for visitors to learn about the particular uniqueness and individuality of its character as declared by interviewees IV, VII, and IX.

\section{Theme Three: Improved place identity [after gating]}

The study reveals that gating has reinforced the social prestige of the majority of the participants. The modern well-designed gates promoted a sense of arrival at a worthwhile destination. (Atalla, Fiki, \& Nagar, 2014) argues that this is about people's need for the high evaluation of themselves, for self-respect or self-esteem, and for the esteem of others.

Domain 2: Management and maintenance (one theme and five codes were identified, figure 7)

Figure (6) Management and maintenance domain and its related theme and codes visualized using the Atlas's network function.

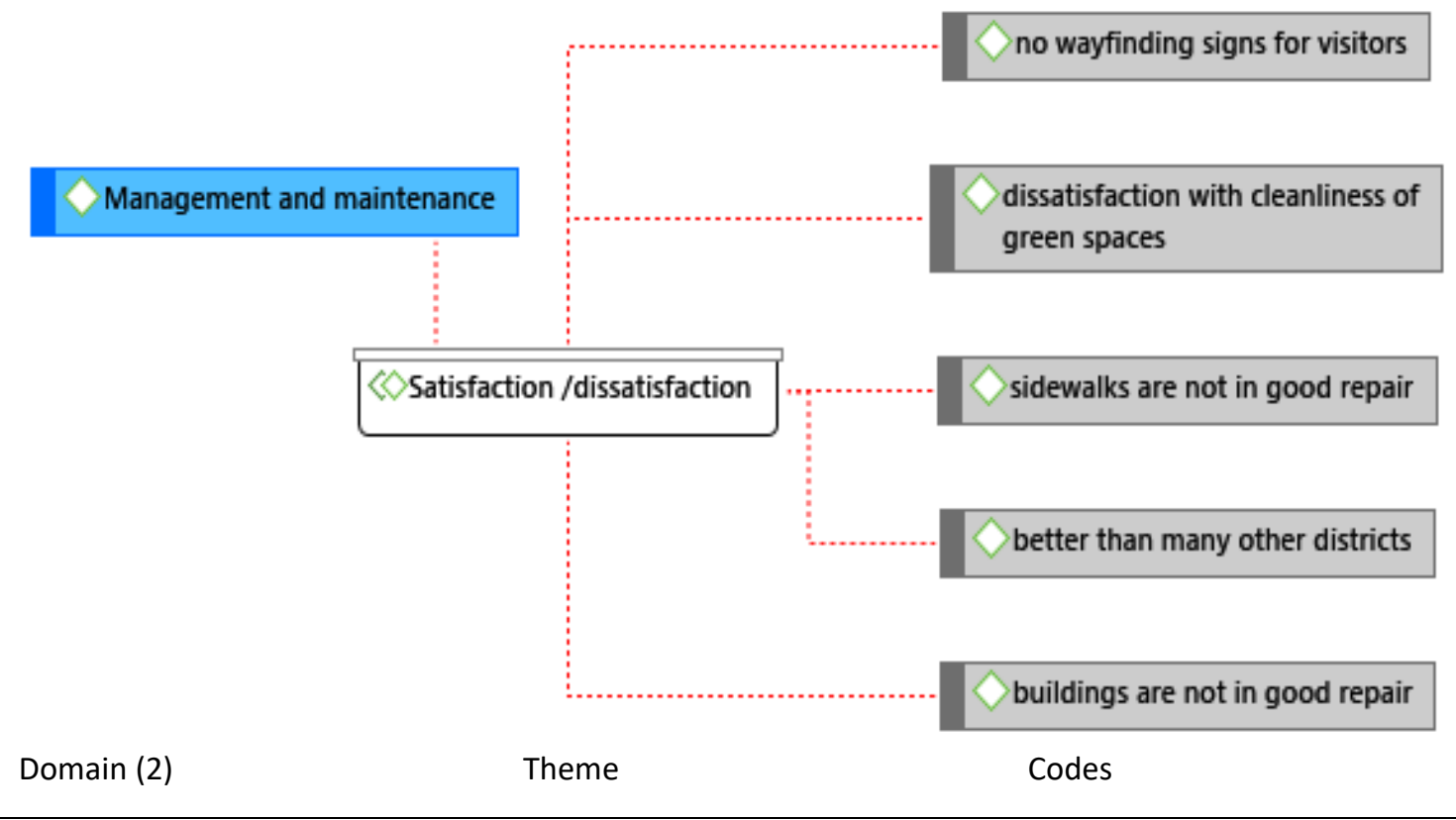

Theme Four: Satisfaction/dissatisfactions with management and maintenance

The study revealed that interviewees shared many concerns about the management and maintenance of their residential environment such as; buildings and sidewalks are not in good repair, no wayfinding signs for visitors "it was always tricky to find an address or to find the way back to the highway" as claimed by interviewee IV, dissatisfaction with cleanliness of green spaces (interviewees, V, VII, and IX). The gates installation has not improved these problems. However, it has been argued that the management and maintenance in this area are much better than many other locations, but still hasn't reached the high standard as it has been before (interviewees IV, VIII, and IX).

RQ2: Have feelings of privacy changed after gating?

Domain 3: Privacy (three themes and nine codes were identified, figure 8) 
Figure (7) Privacy domain and its related themes and codes visualized using the ATLAS.ti network function.

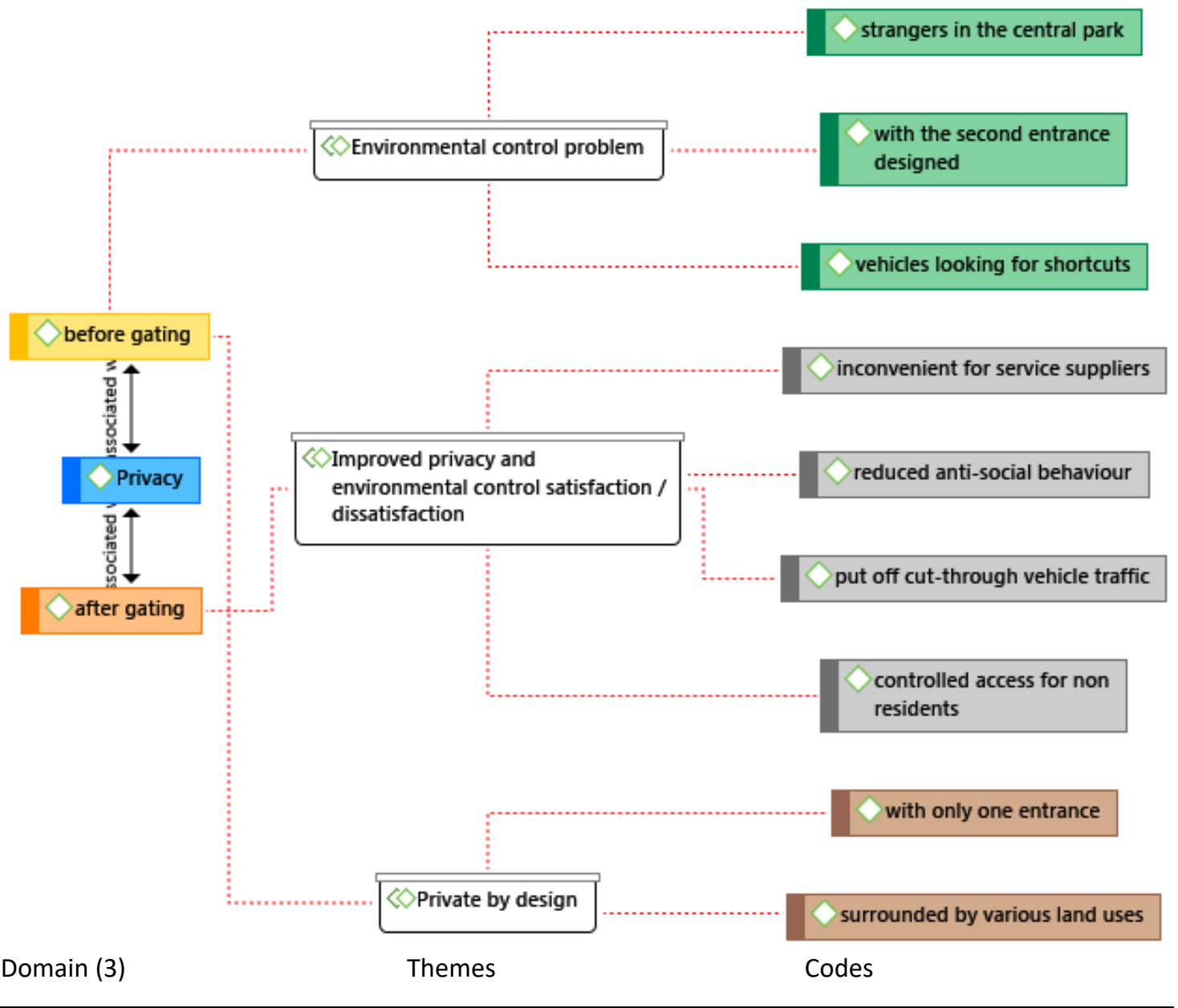

Theme Five: 'Private by design' [before gating]

Participants' views highlighted that the housing area was 'private by design' as it was surrounded by various land use zones, also it was more private when there was only one entrance (interviewees I, II, III, IV, V, VI, VII, and VIII).

\section{Theme six: Environmental control problem [before gating]}

After the second entrance was designed, the residential streets were overrun by vehicles looking for shortcuts, "they continued to ply till late into the night" declared interviewee VI. Moreover, participants weren't comfortable with the non-residents who came to picnic in the park since it was covered with trash in no time (interviewees $\mathrm{VI}$ and IX).

Theme Seven: Improved privacy and environmental control [after gating]

All interviewees declared that gating put off cut-through motor vehicle traffic, controlled access for non-residents, and reduce anti-social behaviour.

RQ3: Is there any difference in social behaviour before and after gating? 
Domain 4: Community ties (three themes and seven codes were identified, figure 9)

All interviewees stated that gating had no effect on social behaviour; people in this area can be trusted as "it is a close-knit community" (interviewee VIII). There is an evident homogeneity between residents, they share the same values, and they are willing to help each other (interviewees III, VII, and IX). Most importantly, the study revealed that social behaviour differs according to the age group and the length of residency as presented in the following themes.

Figure (8) Community ties domain and its related themes and codes visualized using the ATLAS.ti network function

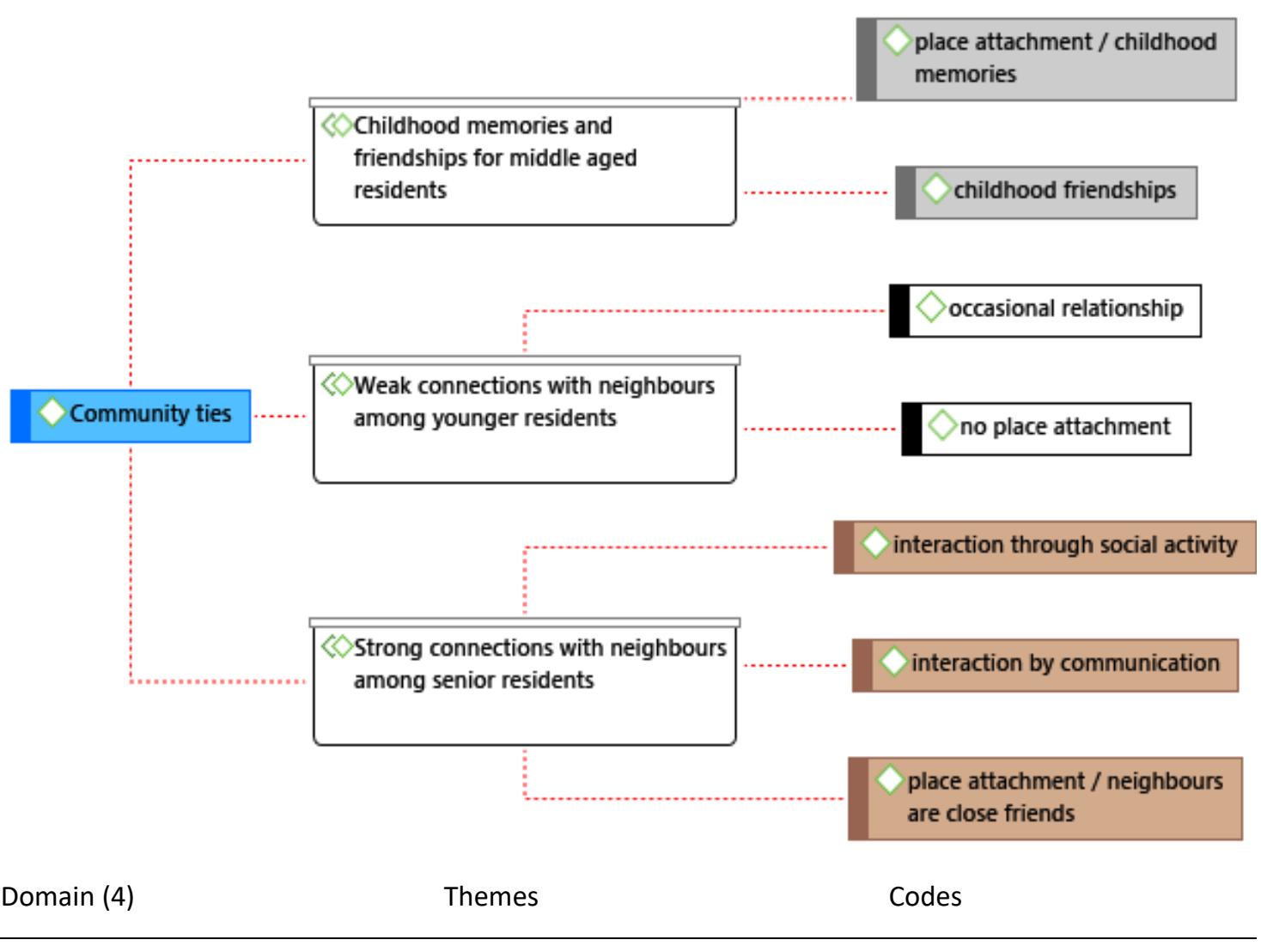

Theme Eight: Strong connections with neighbours among senior residents

The first generation of inhabitants (age group $>65$ years and length of residency $>35$ years) were more likely to develop a strong relationship with their neighbours. Interaction by communication was declared by interviewees VII and IX, also interaction through social activity was declared by interviewees I and III.

\section{Theme Nine: Childhood memories and friendships for middle-aged residents}

The second-generation (age group $35-58$ years and length of residency $>20$ years are more likely to keep their neighbourhood friendship ties. Interviewee II declared that play opportunities and physical safety enhanced children access to play and to friends. 


\section{Theme Ten: Weak connections with neighbours among younger residents}

The third generation (age group $<20$ years and length of residency $<20$ years) was not keen to develop a strong relationship with their neighbours.

RQ ₹: Have feelings of safety changed after gating?

Domain 5: Safety and security feelings (two themes and eight codes were identified, figure 10)

Figure (9) Safety and security domain and its related themes and codes visualized using the ATLAS.ti network function.

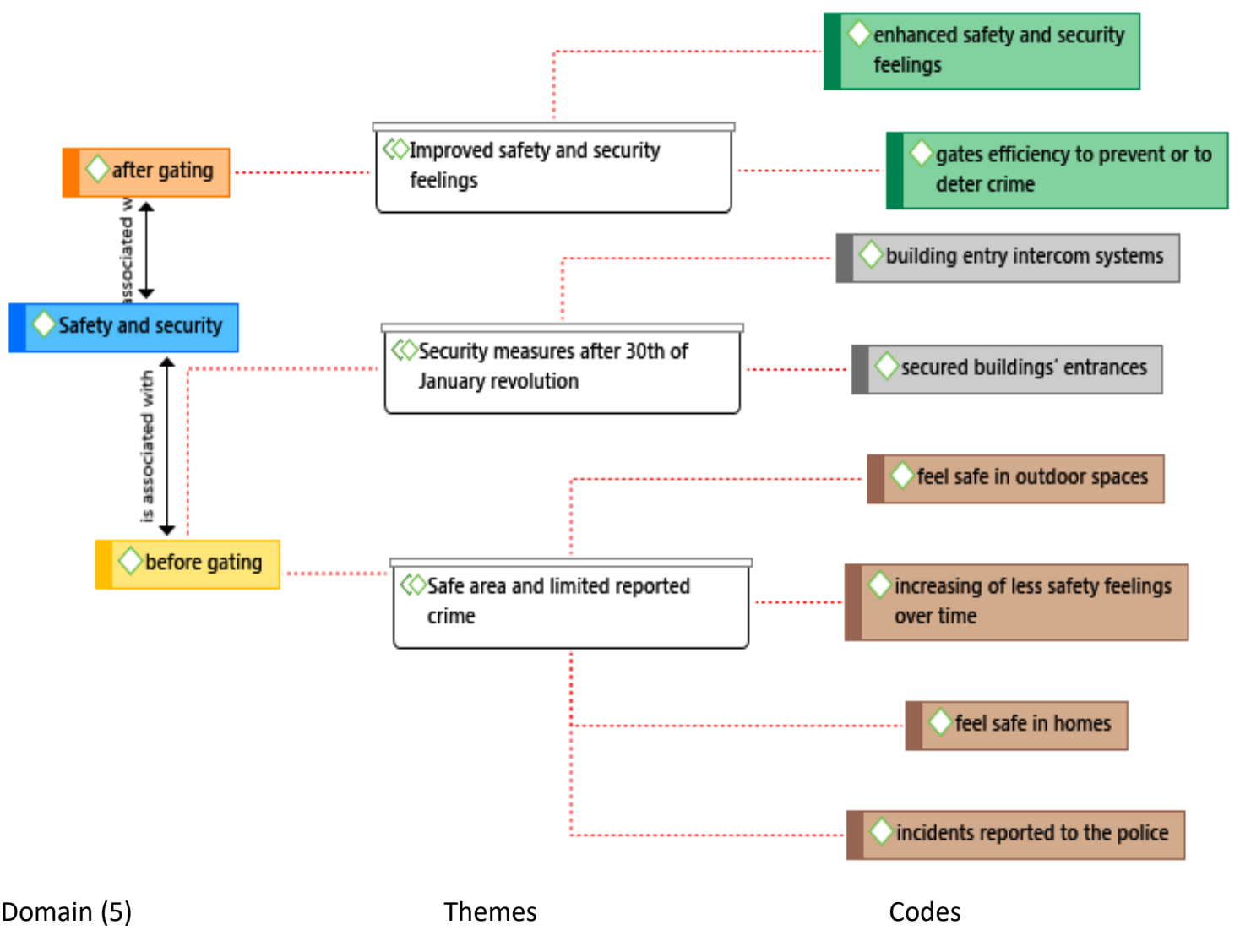

\section{Theme Eleven: Safe area and limited reported crime [before gating]}

People in this area feel safe all time; participants stated that they feel safe in their homes as well as in the shared open spaces. Only limited incidents had been reported to the police (burglary, theft of a car, theft from a car). Interviewees II and VI claim that the existence of the nearby military areas and guardsmen reinforced security feelings. However, some interviewees declared that less safety feelings are increasing over time in this area and the entire city.

Theme Twelve: Security measures after the $25^{\text {th }}$ of January revolution [before gating] 
Security measures had been taken only after the 25th of January revolution. The majority of interviewees declared that during this period they closed their buildings' entrances and installed entry intercom systems.

\section{Theme Thirteen: Improved safety and security feelings [after gating]}

The study revealed that the enclosure had enhanced safety and security feelings. All the interviewees asserted that the existence of gates is a must, although views varied regarding gates efficiency to prevent or to deter crime (interviewees III, V, and $\mathrm{VI})$. Interviewee I referred to a well-said proverb: "the closed-door prevents the chasing destiny".

RQ 5: What are resident's views concerning gates?

Attitudes towards gating (two themes and four codes were identified, figure 11)

Figure (10) Attitudes towards gating visualized using the ATLAS.ti network function.

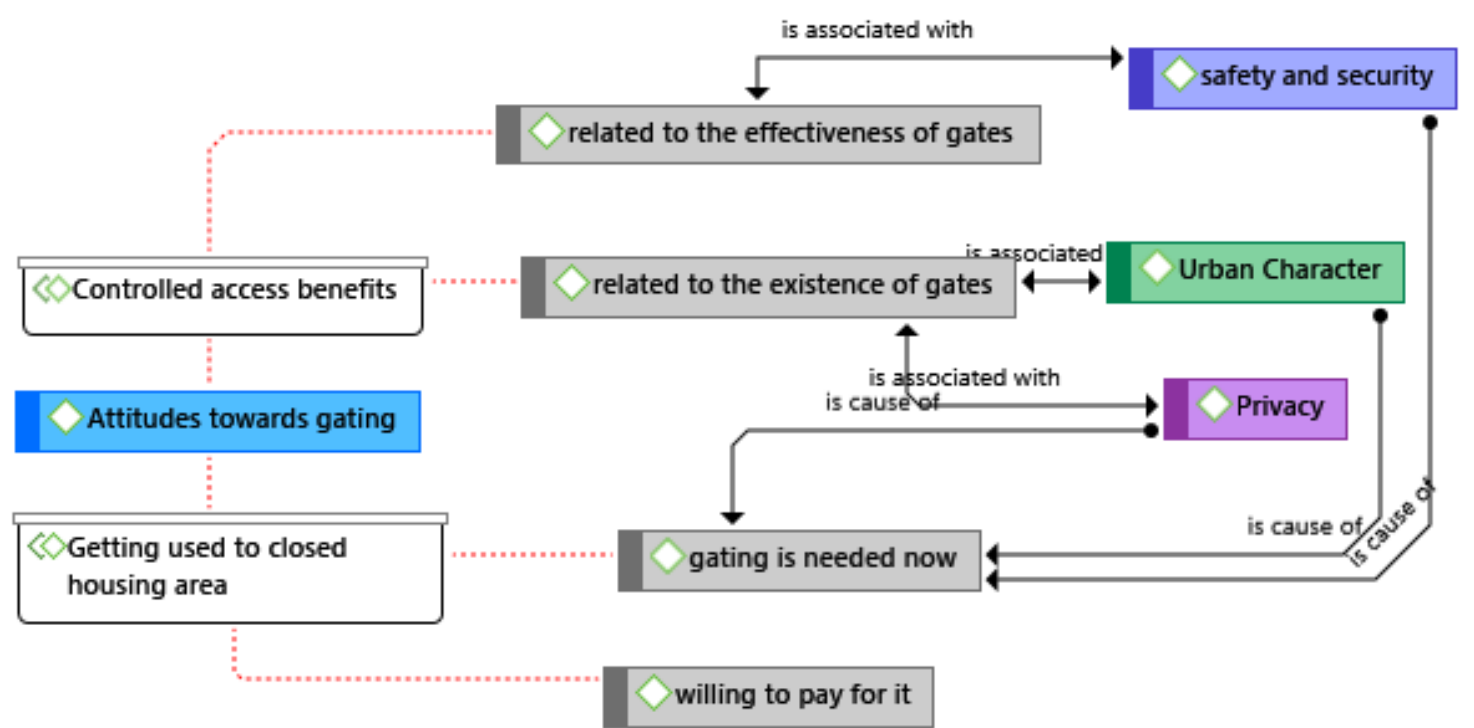

Theme Fourteen: Controlled access benefits [existence vs effectiveness of gates benefits]

Advantages and disadvantages of gating as declared by interviewees are presented in the following table 4 . These views dovetail nicely with the existing literature about gated communities (Grant, 2007; LeGoix, 2005; Manzi \& Smith-Bowers, 2008; Smets, 2005). Interviewee $V$ declared that the existence of gates means that privacy is achieved while the effectiveness of gates means that safety is achieved. Taking this note into account, advantages and disadvantages of gating mentioned by the interviewees are classified according to the predefined domains, which in their turn are categorized according to their relation to the 'existence of gates' or the 'effectiveness of gates' as shown in table 4. (Effectiveness of gates necessitates their existence, so if the gates are effective they could provide the effectiveness related benefits as well as the existence related benefits).

Results indicate that benefits from gating are more related to the existence of gates than its effectiveness. Privacy and environmental control is a paramount advantage 
to interviewees who assert that their housing area should be gated off to tackle antisocial behavior. (Smets, 2005) opined that enclosed space provides an advantage for residents to manage their interactions with others, and to determine the level of social contact they want with outsiders. In other words, by these internal and external forces, the inclusion of the like-minded goes together with the exclusion of others; "exclusion and cohesion are not opposite but complementary realities" p. 14.

Table (2) Advantages and disadvantages of gating as mentioned by interviewees.

\begin{tabular}{|c|c|c|c|}
\hline Advantages / Disadvantages & Domains & & \\
\hline $\begin{array}{l}\text { - } \text { gating has controlled unwanted strangers } \\
\text { using the area (all interviewees) } \\
\text { - } \text { gating has increased privacy (five } \\
\text { interviewees) }\end{array}$ & $\begin{array}{c}\text { Privacy and } \\
\text { Environmental Contro }\end{array}$ & 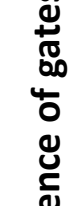 & \\
\hline $\begin{array}{l}\text { - } \text { gating has improved the image of the area } \\
\text { (four interviewees) } \\
-\quad \text { gating has increased property value (three } \\
\text { interviewees) }\end{array}$ & Urban Character & & 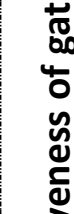 \\
\hline $\begin{array}{l}\text { - } \text { gating has made the area safer (seven } \\
\text { interviewees) } \\
\text { - } \text { gating has been inconvenient for service } \\
\text { suppliers such as taxi services (two } \\
\text { interviewees) }\end{array}$ & Safety and Security & & 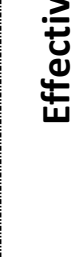 \\
\hline
\end{tabular}

Theme Fifteen: Habituate [getting used to live in a closed housing area]

Most importantly to note that the majority of the interviewees didn't feel they needed gating before, but now, they get used to residential enclosure and they are willing to pay to keep gates in place.

\section{CONCLUSIONS}

This study investigates the role of gating in residential satisfaction; it examines how gating a previously non gated residential development affects residents' satisfaction in five domains: (1) urban character; (2) management and maintenance; (3) privacy and environmental control; (4) community ties; and (5) safety and security feelings. It aims to understand attitudes towards gates installation since these residents have experienced the two different settings; non gated and gated.

The study revealed that community ties, management and maintenance domains haven't changed after gating while urban character, safety and security, privacy and environmental control domains have improved and so residents' quality of life - it has been argued that residents' quality of life was related to feelings of security, physical safety, protection and environmental comfort (Kowaltowski et al., 2006).

The results also indicate that the impact of gates installation on residents' satisfaction is twofold; benefits related to gates' existence and benefits related to gates' effectiveness. The existence of well-designed gates ameliorates the image of the area, increases property value, and enhances people's desire for prestige (urban character domain). The presence of gates has also put off cut-through vehicle traffic, controlled access for non-residents, and reduced anti-social behaviour (privacy and 
environmental control domain). On the other hand, gates' effectiveness boosts safety and security feelings-if not preventing but at least deterring crime (safety and security domain).

Based on this, it seems that it was the deficiency on the part of the planning regime and the public locality system that arise the need for gating this residential development. Moreover, the findings highlight that the residents are getting used to live in a closed housing area; they give in to gating temptation and are willing to pay to keep the gates.

Since people are convinced and attracted by this type of urban enclosure how can we alleviate the negative impacts of gated residential areas? The answer to this question is certainly noteworthy to sustain our cities' liveability and connectivity.

While the main focus of the presented case study is to explore experiences, perceptions, and feelings towards gating, lessons can be inferred on how to soften the boundary effect: two principles in design were applicable. One is that the enclosure size was easily integrated with the local urban neighbourhood and adjacent urban road network. The other principle was diversifying the facilities and services available at the boundaries.

\section{ACKNOWLEDGEMENTS}

This research paper is a part of the researcher's diploma thesis conducted at the American University in Cairo. The author wishes to thank the staff of the Social Research Center of AUC who provided insight and expertise that greatly assisted the research. The author, however, bears full responsibility for the paper.

\section{FUTURE RESEARCH}

Other findings of this study actually suggest future research activities for addressing biophilic design and the development of place attachment.

\section{REFERENCES}

Adriaanse, C. C. M. (2007). Measuring Residential Satisfaction: a residential environmental satisfaction scale (RESS). J Housing Built Environ, 22(287-304).

Atalla, H. L., Fiki, S. E., \& Nagar, S. E. (2014). A Qualitative Investigation to the Fulfillment of Human Needs in Gated Communities, with Reference to Cairo - Egypt. International Journal of Sustainable Human Development, 2(3), 126-136.

Baškarada, S. (2014). Qualitative Case Studies Guidelines. The Qualitative Report, 19(40), 1-18.

Baxter, P., \& Jack, S. (2008). Qualitative Case Study Methodology: Study Design and Implementation for Novice Researchers. The Qualitative Report, 13(4), 544 - 559. Retrieved from http://www.nova.edu/ssss/QR/QR513-544/baxter.pdf.

Berköz, L. (2009). Comparing the Residential Developments in Gated and Non-Gated Neighborhoods in Istanbul. ITU A/Z, 6(1), 41-59.

Bonde, D. (2013). Qualitative Interviews: When Enough is Enough, available at: www.researchbydesign

Boyce, C., \& Neale, P. (2006). Conducting In-Depth Interviews: A Guide for Designing and Conducting In-Depth Interviews for Evaluation Input. Watertown, MA, USA: Pathfinder International.

Creswell, J. W. (2014). Research Design: Qualitative, Quantitative, and Mixed Methods Approaches (Fourth ed.). Thousand Oaks, California: SAGE Publications, Inc.

ElSayed, E. N. S. (2016). Residents' Satisfaction at Gated Communities in Egypt - Case Study: New Cairo City in Greater Region (GCR). International Journal of Scientific \& Engineering Research, 7(4), 1185-1196. 
Fusch, P. I., \& Ness, L. R. (2015). Are We There Yet? Data Saturation in Qualitative Research. The Qualitative Report, 20(9), 1408-1416. Retrieved from http://www.nova.edu/ssss/QR/QR1420/1409/fusch1401.pd.

Grant, J. (2007). Two Sides of a Coin? New Urbanism and Gated Communities. Housing Policy Debate, 18(3), 481-501.

Guest, G., Bunce, A., \& Johnson, L. (2006). How Many Interviews Are Enough?: An Experiment with Data Saturation and Variability. Field Methods, 18(1), 59-82.

Hesse-Biber, S. (2010). Analyzing Qualitative Data: With or without software. Retrieved 10-11, 2016, from www.bumc.bu.edu/crro/files/2010/07/Hesse-Bieber-4-10.pdf

Hodkinson, S. (2012). The New Urban Enclosures. City: analysis of urban trends, culture, theory, policy, action, 16(5), 500-518.

Jiboye, A. D. (2012). Post-Occupancy Evaluation of Residential Satisfaction in Lagos, Nigeria: Feedback for Residential Improvement. Frontiers of Architectural Research, 1, 236-243.

Kohlbacher, F. (2005). The Use of Qualitative Content Analysis in Case Study Research. Forum Qualitative Sozialforschung / Forum: Qualitative Social Research, 7(1), Art. 21.

Kowaltowski, D. C. C. K., da Silva, V. G., Pina, S. A. M. G., Labaki, L. C., Ruschel, R. C., \& Moreira, D. C. (2006). Quality of Life and Sustainability Issues As Seen By the Population of Low Income Housing in the Region of Campinas, Brazil. Habitat International, 30, 1100-1114.

Krefting, L. (1991). Rigour in Qualitative Research: The Assessment of Trustworthiness. American Journal of Occupational Therapy, 45, 214-222.

LeGoix, R. (2005). The Impact of Gated Communities on Property Values: Evidence of Changes in Real Estate Markets -Los Angeles, 1980-2000. Paper presented at the Territory Control and Enclosures, Pretoria, Rep. of South Africa.

Mack, N., Woodsong, C., M.Macqueen, K., Guest, G., \& Namey, E. (2005). Qualitative Research Methods: A Data Collector's Field Guide: Family Health International.

Manzi, T., \& Smith-Bowers, B. (2008). The Politics of Gating: A response to Private Security and Public Space. The European Journal of Spatial Development.

Miles, M. B., \& Huberman, A. M. (1994). Qualitative Data Analysis: An Expanded Source Book (second ed.). Thousand Oaks, CA.: SAGE Publications.

Mohd, T., Johari, N., Ghani, R. A., \& Rahman, N. A. Y. A. (2015). The Impact of Gated and Guarded Development Concept from the Social Aspect: Non-resident perspective. Procedia - Social and Behavioral Sciences, 170, 567 - 574.

O'connor, H. (2003). A Step-by-Step Guide to Qualitative Data Analysis. Pimatiziwin: A Journal of Aboriginal and Indigenous Community Health, 1(1), 64-90.

Ogu, V. I. (2002). Urban Residential Satisfaction and the Planning Implications in a Developing World Context: The Example of Benin City, Nigeria. International Planning Studies, 7(1), 37-53.

Phillips. D. R., Siu, O.-L., Yeh, A. G. O., \& Cheng, K. H. C. (2004). Factors influencing older persons' residential satisfaction in big and densely populated cities in Asia: A case study in Hong Kong. Ageing International, 29(1), 16-70.

Seidman, I. (2006). Interviewing as Qualitative Research: A Guide for Researchers in Education and the Social Sciences (Third ed.). New York, NY: Teachers College Press.

Silverman, D. (1997). Active Interviewing. In: Qualitative Research: Theory, Method, and Practice (pp. 113-129). New Delhi: SAGE Publications.

Smets, P. ( 2005, 23-27 August). Gated 'communities': their lifestyle versus urban governance. Paper presented at the 45th meetings of the European Regional Science Association, "Land Use and Water Management in a Sustainable Network Society", Vrije Universiteit Amsterdam. [Online from http://www.feweb.vu.nl/ersa2005/final papers/403.pdf.

Stake, R. E. (1995). The Art of Case Study Research. Thousand Oaks, CA: SAGE Publications.

Yin, R. K. (2003). Case Study Research: Design and Methods (Third ed.). Thousand Oaks, California: SAGE Publications.

Yin, R. K. (2009). Case Study Research: Design and Methods (Fourth ed.). Los Angeles: SAGE Publications. 


\section{NOTES}

i Propositions can be equated with hypotheses in that they both make an educated guess to the possible outcomes of the research study. Where Yin (2003) uses "propositions" to guide the research process, Stake (1995) applies what he terms "issues" (Baxter \& Jack, 2008), p. 552.

ii The case is "a phenomenon of some sort occurring in a bounded context" (Miles \& Huberman, 1994; Yin, 2003), p. 25

iii "A common question about doing interviews is whether to record them. Using recording devices is a matter of personal preference. Audiotapes certainly produce a more accurate rendition of any interview than any other method. However, a recording device should not be used when (a) an interviewee refuses permission or appears uncomfortable in its presence, (b) there is no plan for transcribing or systematically listening to the contents of the electronic records - a process that takes enormous time and energy, (c) the investigator is clumsy enough with mechanical devices that the recording creates distractions during the interview itself, or (d) the investigator thinks that the record device is a substitute for "listening" closely throughout the course of an interview" (Yin, 2003), p.94.

iv It has been argued that the use of one case is similar to the use of one experiment, "in this sense, the case study, like the experiment, does not represent a 'sample', and the investigator's goal is to expand and generalise theories [analytical generalisation] and not to enumerate frequencies [statistical generalisation]" (Baškarada, 2014), p. 5.

${ }^{\vee}$ The researcher shows how he will protect confidentiality by stating that he will not reveal anything he learns to other participants or members of the community. "You know, I always promise to keep what people tell me confidential, so I can't tell you who else I have seen or what anyone has said. This also means that I will not be able to tell anyone that you and I had this interview, nor will I talk to anyone about what you tell me today" (Mack et al., 2005), p. 31.

${ }^{\mathrm{vi}}$ Social desirability bias is a social science research term that describes a type of response bias that is the tendency of survey respondents to answer questions in a manner that will be viewed favorably by others. It can take the form of over-reporting "good behavior" or underreporting "bad" or undesirable behavior. Source: https://en.wikipedia.org/wiki/Social_desirability_bias

vii Memoing is a critical link between interview data and creation of codes and categories. It includes initial thoughts on data analysis (what does the data say?) and potential interpretations (what does it mean?) (Hesse-Biber, 2010). 